\title{
A parameter recovery model for estimating black spruce diameter distributions within the context of a stand density management diagram
}

\author{
by P.F. Newton ${ }^{1,2}$, Y. Lei ${ }^{3}$ and S.Y. Zhang ${ }^{4}$
}

\begin{abstract}
The objectives of this study were to develop and subsequently demonstrate a parameter prediction approach for estimating black spruce (Picea mariana (Mill.) BSP) diameter frequency distributions within the context of a stand density management diagram (SDMD). The approach consisted of three sequential steps: (1) obtaining maximum likelihood estimates for the location, scale and shape parameters of the Weibull probability density function for 153 empirical diameter frequency distributions; (2) developing and evaluating parameter prediction equations in which the Weibull parameter estimates were expressed as functions of stand-level variables based on stepwise regression and seemingly unrelated regression techniques; and (3) explicitly incorporating the parameter prediction equations into the SDMD modelling framework. The results indicated that the Weibull function was successful in characterizing the diameter distributions within the sample stands: the fitted distributions exhibited no significant $(p \leq 0.05)$ differences in relation to their corresponding observed distributions, based on the Kolmogorov-Smirnov test. The parameter prediction equations described 94, 94 and $89 \%$ of the variation in the location, scale and shape parameter estimates, respectively. Furthermore, evaluation of the recovered distributions in terms of prediction error indicated minimal biases and acceptable accuracy. As demonstrated, incorporating the parameter prediction equations into an algorithmic version of the SDMD enabled the prediction of the temporal dynamics of the diameter frequency distribution by initial density regime and site quality. Additionally, an executable version of the resultant algorithm with instructions on acquiring it via the Internet is provided.
\end{abstract}

Key words: 3-parameter Weibull probability density function, stepwise and seemingly unrelated regression, predictive error, product value, algorithm, Internet

Les objectifs de cette étude étaient de développer et par la suite d'utiliser une approche de récupération de paramètres pour estimer les distributions de fréquence de diamètre de l'épinette noire (Picea mariana (Mill.) BSP) dans le cadre d'un diagramme d'aménagement de la densité d'un peuplement (SDMD). L'approche comportait trois étapes séquentielles : (1) l'obtention du maximum vraisemblable d'estimés pour les paramètres du site, de l'échelle et de la forme de la fonction de probabilité de densité de Weibull pour 153 distributions empiriques de fréquence de diamètre; (2) le développement et l'évaluation des équations de récupération des paramètres dans lesquelles les estimés des paramètres selon Weibull étaient exprimés en tant que fonctions des variables du peuplement selon des techniques de régressions par étape et d'autres techniques de régression apparemment sans rapport, et (3) l'intégration explicite des équations de récupération des paramètres dans le cadre du travail de modélisation SDMD. Les résultats démontrent que la fonction Weibull a réussi à représenter les caractéristiques des distributions de diamètre pour les peuplements échantillons : les distributions ajustées n'ont montré aucune différence significative $(p=0.05)$ relativement aux distributions correspondantes observées, selon un test Kolmogorov-Sminov. Les équations de récupération des paramètres décrivaient 94, 94 et $89 \%$ de la variation pour respectivement les paramètres estimés du site, de l'échelle et de la forme. De plus, l'évaluation des distributions récupérées en terme de prédiction de l'erreur indiquait des biais minimes et une précision acceptable. Tel que démontré, l'incorporation des équations de récupération des paramètres dans une version algorithmique du SDMD a permis la prédiction de la dynamique temporelle de la distribution de la fréquence des diamètres selon le régime initial de densité et la qualité de la station. De plus, une version utilisable directement de l'algorithme final accompagnée des instructions relative à son obtention par Internet est fournie.

Mots-clés: fonction de probabilité de densité à trois paramètres de Weibull, régression reliée et apparemment différente, erreur de prédiction, valeur du produit, algorithme, Internet

\section{Introduction}

The stand density management diagram (SDMD) is a decision-support tool used to assist forest managers in designing density control regimes required for the realization of specified stand-level management objectives (e.g., Ando 1962, Drew

\footnotetext{
${ }^{1}$ Research Scientist, Analytical Stand Dynamics Research, Canadian Forest Service - Ontario, Natural Resources Canada, 1219 Queen St. East, Sault Ste. Marie, Ontario P6A 2E5. E-mail: pnewton@ nrcan.gc.ca

${ }^{2}$ Author to whom all correspondence should be addressed.

${ }^{3}$ Associate Professor, Department of Forest Management and Statistics, Research Institute of Forest Resource Information Techniques, Chinese Academy of Forestry, P.O. Box 9, Beijing 100091, P.R. China. E-mail: lycai@ info.forestry.ac.cn ${ }^{4}$ Senior Scientist/Group Leader, Resource Assessment and Utilization Group, Forintek Canada Corp., 319, rue Franquet, Sainte-Foy, Quebec G1P 4R4. E-mail: tony.zhang@qc.forintek.ca
}

and Flewelling 1979, Newton and Weetman 1993). Structurally, SDMDs graphically illustrate the relationships between stand yield, density and mortality employing empirical and functional relationships derived from competition and self-thinning theory (Drew and Flewelling 1977, Jack and Long 1996, Newton 1997a). These relationships represent the cumulative effect of various underlying competition processes on tree and stand yield parameters (e.g., reciprocal equations of the competition-density and yield-density effect (Kira et al. 1953, Shinozaki and Kira 1956); and the self-thinning rule (Yoda et al. 1963)). The temporal dependency of these processes is governed by the intensity of competition and site quality as expressed by relative density index and site index, respectively.

Although SDMDs have been developed for numerous commercially important species throughout the world, their 
utility has been largely limited to evaluating density management outcomes in terms of mean tree size and standlevel volumetric yields (Newton 1997a). Recently, maximizing product value rather than volumetric yield has become an important management objective as exemplified by corporate trends in Sweden (e.g., Hagner 2000) and North America (e.g., Brunsdon 2000, Terry 2000).

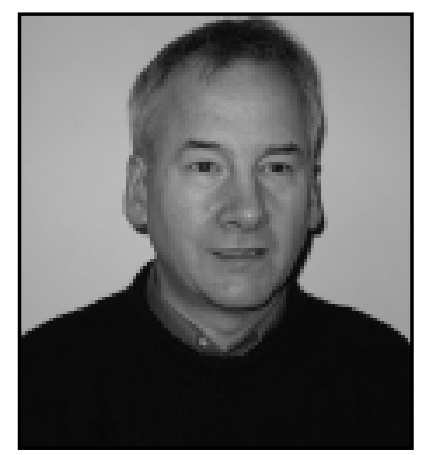

P.F. Newton

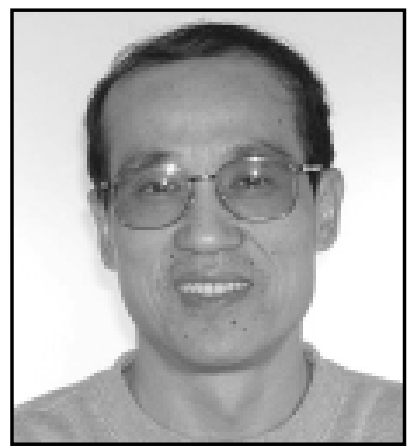

Y. Lei

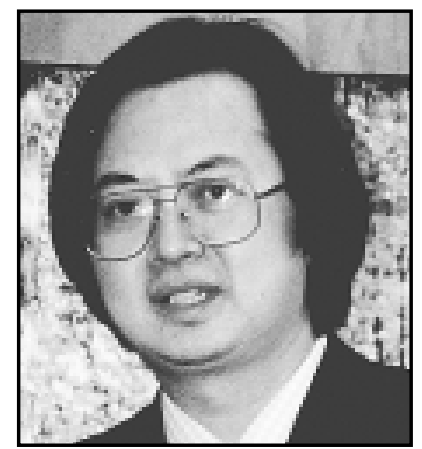

S.Y. Zhang
However, product value calculations require an estimate of the underlying diameter distribution given the inherent relationship between monetary value and tree size (e.g., Zhang and Chauret 2001). Consequently, the objectives of this study were to develop and subsequently demonstrate a parameter prediction approach for estimating black spruce (Picea mariana (Mill.) BSP) diameter frequency distributions within the context of a SDMD (Newton and Weetman 1993, Newton 1997b). Additionally, an algorithmic version of the extended SDMD with instructions on its obtainment via the Internet is provided.

\section{Method}

\section{Data description}

The data base consisted of 153 diameter frequency distribution measurements obtained from 42 0.081-ha permanent sample plots (PSPs) located in naturally regenerated black spruce stands ( $>90 \%$ black spruce by basal area) throughout Forest Section B28a-Grand Falls of the Canadian boreal forest region (Rowe 1972). Although the PSPs were concentrated within the Exploits River and Red Indian Lake watersheds, their disturbance history and structural characteristics were representative of the upland black spruce stand type (Newton and Smith 1988). The PSPs were established in 1947-48 and remeasured from two to three times at approximately ten year intervals: all 42 PSPs were remeasured twice (1957-58/1967-68) and 27 were remeasured a third time (1978), yielding a total of 153 measurements.

The data collected at the time of each plot measurement included the following: (1) a species-specific tally of all living trees greater than $1.5 \mathrm{~cm}$ in diameter at breast-height by diameter class; specifically, trees were stratified into 12 diameter classes $\left(D_{(i)}\right.$ where $i=1, \ldots, 12 ; 1.5<D_{(1)}(\mathrm{cm}) \leq 4.0,4.0<$ $\left.D_{(2)}(\mathrm{cm}) \leq 6.6, \ldots, 29.4<D_{(12)}(\mathrm{cm}) \leq 32.0\right)$ resulting in a grouped diameter frequency distribution; and (2) total height $( \pm 0.31 \mathrm{~m})$ and breast-height age measurements on approximately ten dominant and (or) codominant black spruce trees from which mean dominant height $\left(H_{d} ; \mathrm{m}\right)$ and breast-height age $(A ; y r)$ were calculated. Computations included the following: (1) calculating the total density of the living (biotic) population $\left(N_{B}\right.$; stems/ha); (2) calculating the total height for each diameter class employing Page and van Nostrand's (1973) height-diameter regression function

$$
H_{(i)}=12.649+0.1045 D_{(i)} \cdot H_{d(j)}-0.0144 D_{(i)}^{2}
$$

where $H_{(i)}$ is the height of the $i$ th diameter class in feet, $D_{(i)}$ is the diameter class mid-point value in inches, and $H_{d(j)}$ is the mean dominant plot height in feet at the jth measurement, and subsequently converting diameter and height values to their metric equivalents based on Ker's (1974) procedure; (3) calculating individual tree volumes, mean volume $\left(\bar{v} ; \mathrm{dm}^{3}\right)$, total volume $\left(V_{t} ; \mathrm{m}^{3} / \mathrm{ha}\right)$ and merchantable volume $\left(V_{m}\right.$; $\mathrm{m}^{3} / \mathrm{ha}$ ) using Warren and Meades' (1986) volume equations (n., a $0.15-\mathrm{m}$ stump height and a $7.62-\mathrm{cm}$ top diameter (inside-bark) for all trees greater than $9.5 \mathrm{~cm}$ in diameter at breast height were used as merchantability thresholds); and (4) calculating quadratic mean diameter $\left(D_{q} ; \mathrm{cm}\right)$, basal area $\left(G ; \mathrm{m}^{2} / \mathrm{ha}\right)$ and relative density index $\left(P_{r} ; \%\right.$ (Newton and Weetman (1993)). Note, the original grouped diameter frequency distribution tally was delineated by twelve 1-inch-wide diameter classes. The majority of the distributions were positively-skewed with many larger classes with zero counts: specifically, the percentage of measurements with zero counts by diameter class were $0,0,0,1,4,15,49,63,93,97,99$, and $100 \%$ for the $1,2,3,4,5,6,7,8,9,10,11$ and 12-inch diameter classes, respectively. Consequently, in order not to exclude plot measurements due to the lack of diameter classes during the data analysis step, the group diameter frequency distributions were transformed by subdividing each diameter class interval $(2.5 \mathrm{~cm})$ into tenths and subsequently allocating $n_{i} / 10$ trees to each subinterval, where $n_{i}$ is the total number of trees per plot within the $i$ th diameter class. Note, if $n_{i}<10$ than the interval was subdivided into $n_{i}$ intervals and trees allocated on a proportional basis. All other plot measurements were converted to their metric equivalents using standard conversion factors (System of International Units). Additionally, each plot was assigned a site index value $\left(S_{I}\right)$ based on $H_{d}$ and $A$ measurements obtained during the 1957-58 remeasurement (i.e., $S_{I}=H_{d}$ at an $A$ of 50 yr (Newton 1992)). Overall, the stands in which the PSPs were located, represented the commercial range of conditions currently under forest management within central insular Newfoundland (Table 1).

\section{Data analysis}

The diameter distribution at each plot measurement was described by the 3-parameter Weibull probability density function (PDF) (Eq. (1) (Weibull 1951)).

$$
f(D ; a, b, c)=\left\{\begin{array}{l}
\frac{c}{b}\left(\frac{D-a}{b}\right)^{c-1} \exp \left(-\left(\frac{D-a}{b}\right)^{c}\right) \\
0 \text { if } D<a
\end{array}\right.
$$

if $a \leq D \leq \propto$ 
Table 1. Summary of the mensurational characteristics of the stand-level variables including the Weibull parameter estimates derived from the 153 plot measurements

\begin{tabular}{|c|c|c|c|c|c|}
\hline Parameter $^{\text {a }}$ (units) & Mean & Standard deviation & Standard error & Minimum & Maximum \\
\hline$A(\mathrm{yr})$ & 45.2 & - & 11.95 & 14 & 70 \\
\hline$S_{I}(\mathrm{~m})$ & 10.81 & - & 1.34 & 8.09 & 13.35 \\
\hline$H_{d}(\mathrm{~m})$ & 10.25 & - & 2.15 & 4.91 & 15.61 \\
\hline$N_{B}($ stems $/ \mathrm{ha})$ & 6988 & 3207 & - & 1421 & 19410 \\
\hline$P_{r}(\%)$ & 64.02 & 24.96 & - & 6.23 & 118.71 \\
\hline$D^{r}(\mathrm{~cm})$ & 7.35 & - & 1.62 & 3.32 & 14.67 \\
\hline$G^{q}\left(\mathrm{~m}^{2} / \mathrm{ha}\right)$ & 28.01 & 10.87 & - & 1.98 & 52.22 \\
\hline $\bar{v}\left(\mathrm{dm}^{3}\right)$ & 17.40 & - & 10.87 & 2.02 & 98.18 \\
\hline$V_{t}\left(\mathrm{~m}^{3} / \mathrm{ha}\right)$ & 105.86 & 50.73 & - & 4.63 & 242.48 \\
\hline$V_{m}\left(\mathrm{~m}^{3} / \mathrm{ha}\right)$ & 70.25 & 48.78 & - & 0 & 224.14 \\
\hline$\hat{a}^{m}$ & 1.265 & 0.256 & - & 0.048 & 1.520 \\
\hline$\hat{b}$ & 5.876 & 1.897 & _- & 1.887 & 14.516 \\
\hline$\hat{c}$ & 1.482 & 0.339 & - & 0.895 & 2.854 \\
\hline
\end{tabular}

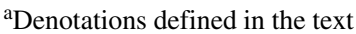

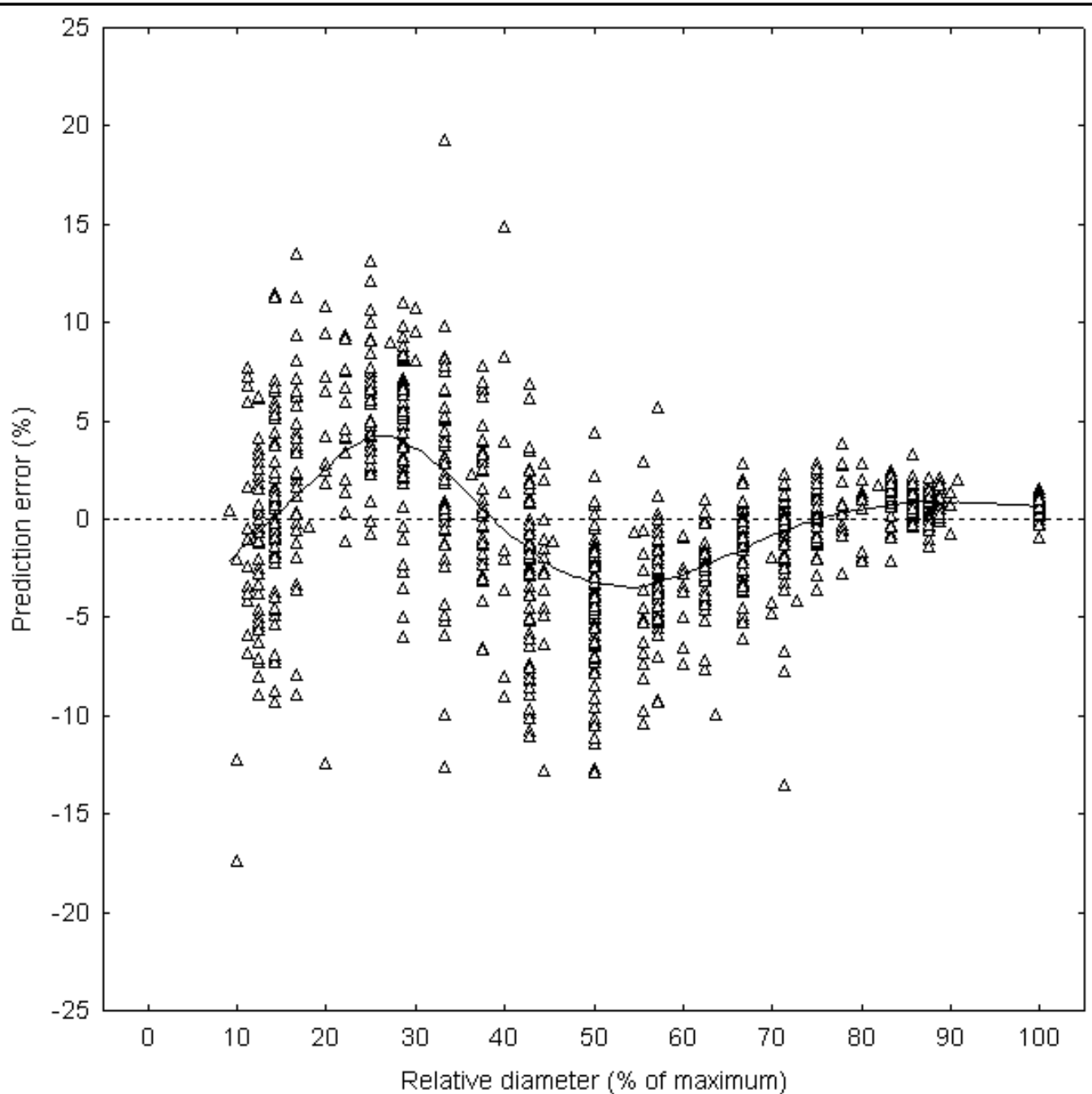

Fig. 1. Relative prediction error-relative diameter scatterplot where the solid curve reflects the overall trend as described by a localized regression function.

where $D$ is the diameter at breast height $(\mathrm{cm}), a$ is the location parameter which is equivalent to the minimum diameter of the distribution, $b$ is the scale parameter which is related to the range of the distribution, and $c$ is the shape parameter which is related to the degree of skewness of the distribution. The Weibull function is frequently used to characterize unimodal diameter distributions within forest stands given its relative simplicity and high degree of flexibility (e.g., Bailey and Dell 1973, Schreuder and Swank 1974, Little 1983, Álvarez et al. 2002). The corresponding 3-param- 


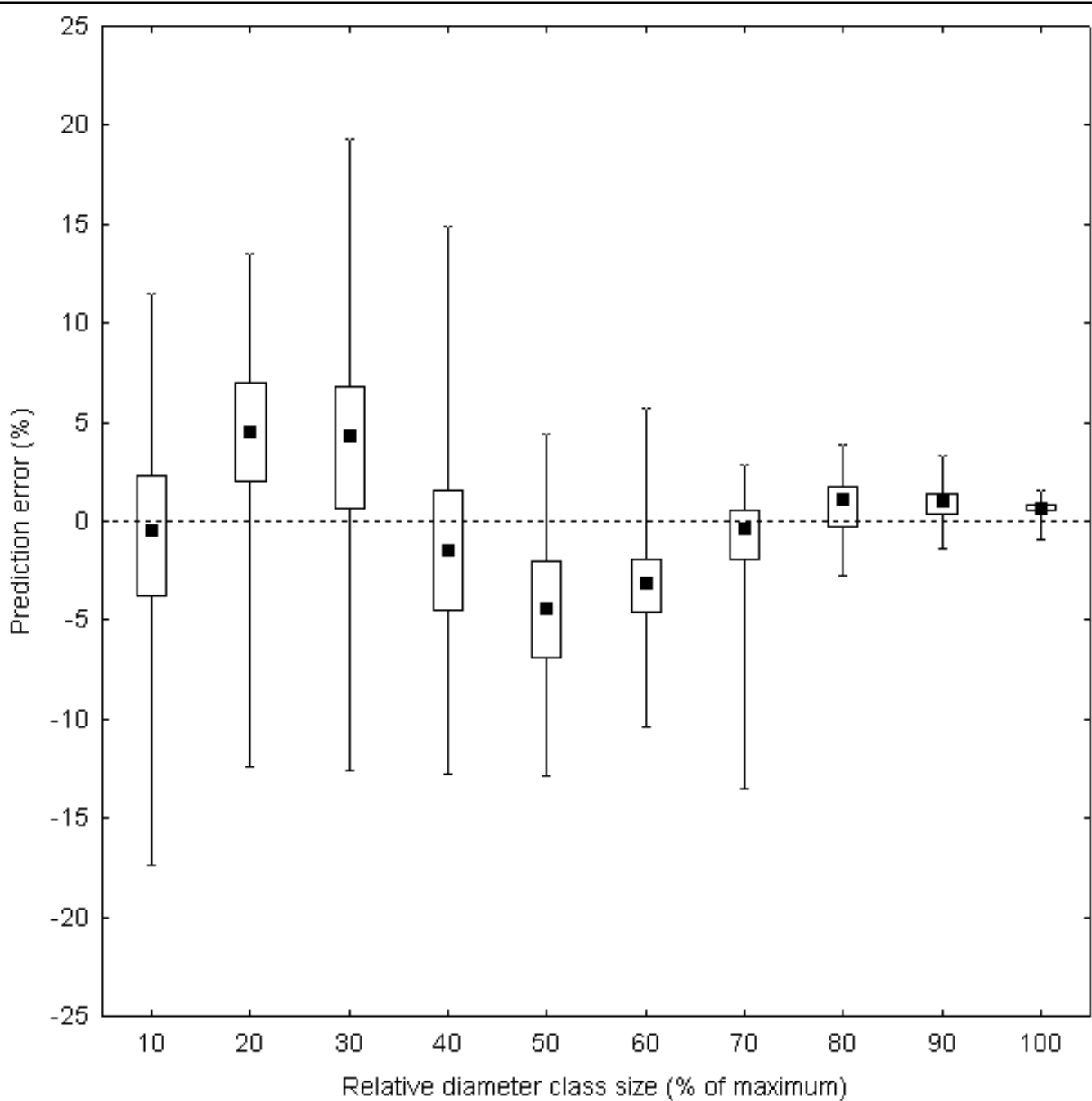

Fig. 2. Box and whisker plots summarizing the distributional characteristics of relative prediction error by relative diameter class size. Denotations: median value is denoted by the solid square within the open rectangle, first and third quartiles are denoted by the lower and upper horizontal sides of the open rectangle, respectively, and minimum and maximum values are denoted by the end points of the lower and upper whiskers, respectively.

eter Weibull cumulative distribution function $(\mathrm{CDF})$ is given by Eq. (2).

$$
F(D ; a, b, c)=1-\exp \left(-\left(\frac{D-a}{b}\right)^{c}\right)
$$

Estimates for $a(\hat{a}), b(\hat{b})$ and $c(\hat{c})$ were obtained via maximum likelihood estimation (MLE) employing SAS's (1999) nonlinear programming procedure. Note, in 10 cases, the initial MLE resulted in negative estimates for the location parameter. In general, parameter $a$ is equivalent to smallest possible diameter within the distribution and hence should range between zero and the minimum observed value (Bailey and Dell 1973). Consequently, for these 10 cases, $a$ was arbitrarily set to 0.76 (the midpoint of the theoretically smallest diameter interval $(0.01-1.52 \mathrm{~cm})$ ), and parameters $b$ and $c$ re-estimated. Each resultant distribution was com- pared with its corresponding observed distribution employing the Kolmogorov-Simirnov (K-S) goodness-of-fit test (Little 1983).

A parameter prediction method was used to predict the Weibull's parameter estimates employing stand-level variables. Specifically, based on preliminary graphical and correlation analyses, $\hat{a}, \hat{b}$ and $\hat{c}$ were expressed as linear functions of $S_{I}, H_{d}, N_{B}, P_{r}, D_{q}, G, \bar{v}$, $V_{t}, V_{m}$ and each other. Stepwise regression analysis was used to identify a set of candidate functional forms based on a 0.01 risk level (Kilkki et al. 1989). Parameter estimates for the resultant system of equations were estimated simultaneously via seemingly unrelated regression (SUR) analysis given that SUR estimation takes into account error covariances across the three equations and is asymptotically efficient in the absence of specification error (Zellner 1962). These equations were evaluated by comparing the recovered grouped diameter frequency distributions to those observed within the sample stands. Specifically, the assessment involved the following sequential steps: (1) estimating parameters $a, b$ and 
Table 2. Prediction error by relative diameter class

\begin{tabular}{|c|c|c|c|c|c|}
\hline $\begin{array}{l}\text { Relative diameter } \\
\operatorname{class}^{\text {a }}(\%)\end{array}$ & $\begin{array}{c}\text { Mean relative } \\
\text { prediction error }^{\mathbf{b}}(\bar{D})\end{array}$ & $\begin{array}{l}\text { Number } \\
\text { of pairs }(n)\end{array}$ & $\begin{array}{l}\text { Normality of errors } \\
\quad(K-S \text { statistic })\end{array}$ & $\begin{array}{l}95 \% \text { prediction } \\
\text { limits for } \bar{D}^{\mathbf{d}}(\bar{D} \pm)\end{array}$ & $\begin{array}{c}95 \% \text { tolerance } \\
\text { limits for } \bar{D}^{\mathrm{e}}(\bar{D} \pm)\end{array}$ \\
\hline 10 & -0.56 & 116 & $0.047 \mathrm{NS}$ & 9.62 & 10.68 \\
\hline 20 & 4.31 & 95 & $0.070 \mathrm{NS}$ & 8.78 & 9.85 \\
\hline 30 & 3.65 & 106 & $0.085 \mathrm{NS}$ & 9.39 & 10.48 \\
\hline 40 & -1.50 & 122 & $0.051 \mathrm{NS}$ & 9.54 & 10.57 \\
\hline 50 & -4.59 & 76 & $0.063 \mathrm{NS}$ & 6.94 & 7.90 \\
\hline 60 & -3.31 & 122 & $0.077 \mathrm{NS}$ & 4.96 & 5.49 \\
\hline 70 & -0.80 & 147 & $0.106^{*}$ & 4.44 & 4.87 \\
\hline 80 & 0.80 & 54 & $0.133^{*}$ & 2.97 & 3.46 \\
\hline 90 & 0.91 & 116 & $0.066 \mathrm{NS}$ & 1.46 & 1.62 \\
\hline 100 & 0.67 & 153 & $0.117^{*}$ & 0.62 & 0.68 \\
\hline
\end{tabular}

aRelative diameter class size (\% of maximum).

${ }^{\mathrm{b}} \bar{D}=\sum_{i=1}^{n}\left(\hat{Y}_{i}-Y_{i}\right) / n$ where $\hat{Y}$ and $Y_{i}$ are the predicted and observed relative frequency values for the $i$ th relative diameter class, respectively.

'Kolmogorov-Smirnov $D$ statistic: rejection and non-rejection of the hypothesis that the errors were normally distributed at the 0.05 probability level is denoted by superscripts * and NS, respectively.

${ }^{\mathrm{d}} \bar{D} \pm \sqrt{1 / n+1 / k} \cdot S \cdot t_{0.975}$ (Reynolds 1984) where $S$ is the standard deviation of the errors, $t_{0.975}$ is the 0.975 quantile of the $t$-distribution with $n-1$ degrees of freedom, and $k$ is the number of future predictions $(k=1)$. Note, the interval corresponding to classes with non-normally distributed errors $(70,80$ and 100$)$ is an approximation (Reynolds 1984).

${ }^{\mathrm{e}} \bar{D} \pm K \cdot S$ (Reynolds 1984) where $K$ is a tolerance factor for the normal distribution based the specified proportion of the future error distribution to be included within the interval $(95 \%)$, sample size $(n)$, and probability level $(p=0.05)$. Note, the interval corresponding to classes with non-normally distributed errors (70, 80 and 100) is an approximation (Reynolds 1984).

$c$ employing the observed stand-level variables for each of the 153 plot measurements; (2) recovering the cumulative diameter distribution and subsequently estimating the group diameter frequency distribution (i.e., calculating the number of trees within each of the 12 diameter classes); (3) calculating the corresponding relative frequency distributions for both the recovered and observed distributions based on total density and maximum diameter; (4) graphically comparing the differential between the recovered and observed relative frequency distributions by relative diameter; and (5) statistically assessing the degree of estimation error by relative size class, employing prediction and tolerance intervals (Reynolds 1984, Gribko and Wiant 1992).

\section{Results}

Table 1 summarizes the mensurational characteristics of the sampled stands including the parameter estimates obtained for the Weibull PDFs. The 153 diameter distributions were well described by the 3-parameter Weibull PDF given the results of the K-S goodness-of-fit test: no significant $(p \leq 0.05)$ lack of fit for any of the 153 distributions. The resultant parameter prediction equations for predicting $a, b$ and $c$ are given by Eqs. (5), (3) and (4), respectively.

$$
\begin{aligned}
\hat{b}= & -0.5326-0.2571 \cdot H_{d}+1.1413 \cdot D_{q}-0.03813 \cdot G \\
& +0.0163 \cdot V_{t} \\
\hat{c}= & 1.8242-0.4485 \cdot D_{q}+0.5029 \cdot \hat{b} \\
\hat{a}= & 1.1409+0.0143 \cdot H_{d}+0.2572 \cdot D_{q}-0.3255 \cdot \hat{b}
\end{aligned}
$$

The approximate multiple coefficients of determination and corresponding residual mean squared errors were respectively: 0.943 and 0.460 for Eq. (3); 0.938 and 0.085 for Eq. (4); and 0.889 and 0.086 for Eq. (5). The system weighted $R^{2}$ for the SUR estimation was 0.927 .

Fig. 1 graphically illustrates the resultant pattern of relative prediction errors in relation to relative diameter following the recovery of the diameter distributions via Eqs. (3), (4) and (5). Generally, the errors exhibited a systematic pattern in which relative errors decreased with increasing relative size. Furthermore, the trend line, as quantified by a localized regression function (Cleveland 1979), suggested over- and under-estimation at the lower and middle size classes, respectively. Examining these errors in terms of relative diameter classes revealed a similar pattern (Fig. 2). Table 2 lists the resultant mean biases and associated $95 \%$ prediction and tolerance limits by relative diameter class. The $95 \%$ prediction interval defines the lower and upper limits of the error to be expected from a single future prediction. The tolerance interval defines the lower and upper limits in which $95 \%$ of the future errors would fall. Collectively, these results suggest that the parameter prediction method based on the 3-parameter Weibull PDF resulted in acceptable predictions given the minimal biases observed (mean/minimum/maximum (\%): -0.04/-4.49/4.31) and the expected prediction (5.87/0.62/9.62) and tolerance intervals (6.56/0.68/10.68) for future errors.

Incorporating the parameter prediction equations into the SDMD modelling framework, as schematically illustrated in Fig. 3, resulted in a stand-level distance-independent distribution model (sensu Porté and Barlelink 2002). Furthermore, in order to facilitate its utility and eliminate userinduced graphical interpolation error, an algorithmic version of the model was developed. Specifically, the original SDMD algorithm (SDMDNI; Newton 1997b) was modified via the explicit incorporation of Eqs. (3), (4) and (5) within the programming code. The resultant algorithm, denoted SDMDNID (Stand Density Management Diagram for Natural stands - Interactive version - Diameter distribution recovery), predicts and tabulates the number of trees (stems/ha) per diameter class $(2,4, \ldots, 30 \mathrm{~cm})$ at each 10 year developmental interval $(10,20, \ldots, 100$ years) for eight user-specified initial densities regimes for a given site quality. Potential users can acquire a copy of the algorithm via the Internet by downloading the SDMDNID.ZIP 


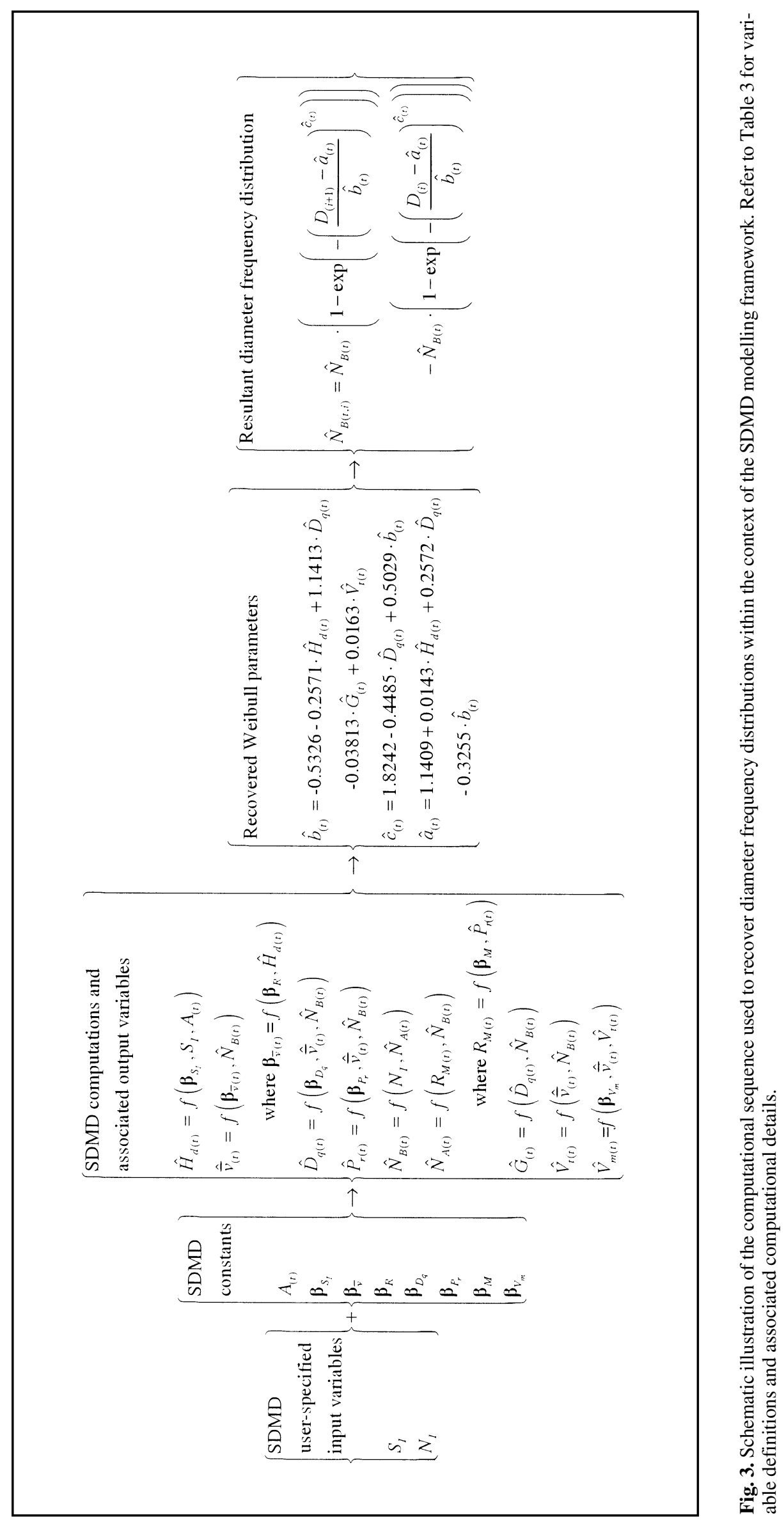




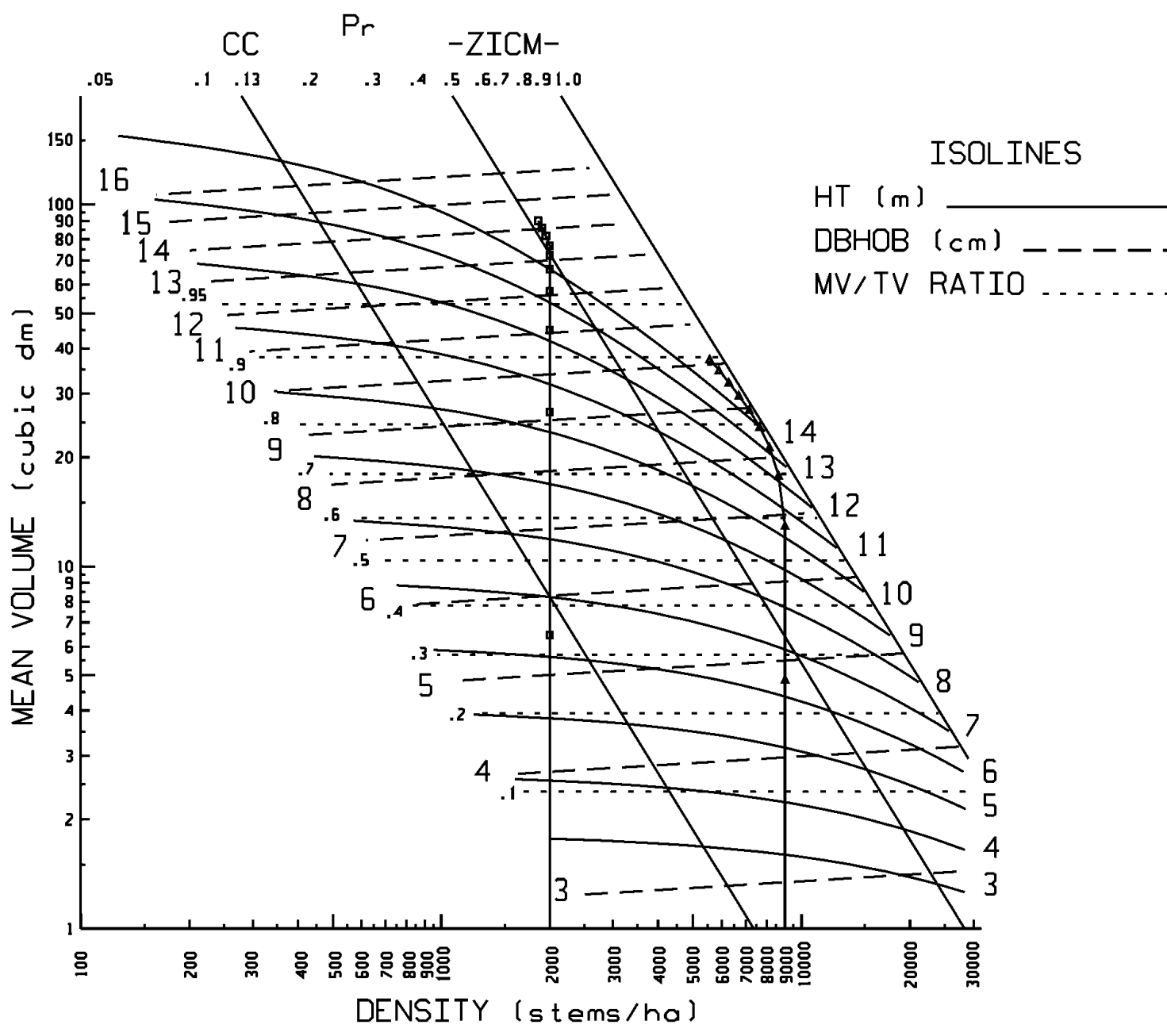

Fig. 4. Stand density management diagram for natural black spruce stands situated on good quality sites $\left(S_{I}=14 \mathrm{~m}\right)$. Principal components include: (1) approximate crown closure line $(C C)$ at a relative density $\left(P_{r}\right)$ of $0.13 ;(2)$ lower limit of the zone of imminent competition-mortality (ZICM) at $P_{r}=0.50$; (3) self-thinning rule at $P_{r}=1.0$; (4) reciprocal equation of the C-D effect at specified mean dominant heights (HT isolines); (5) isolines for quadratic mean diameter (DBHOB) and merchantability ratio (MV/TV); and (6) predicted size-density trajectories (vertical solid lines) with $10 \mathrm{yr}$ interval denotations for 2 of the 8 initial density regimes considered (2000 (square) and 9000 (triangle) stems/ha)

file from the ftp://ftp.glfc.forestry.ca/pnewton/outgoing/ site. Note, this PC-based algorithm is compatible with the Windows 95, 98 or $2000(\leq$ Service Pack 3$)$ (MS Corporation, USA) operation systems. To execute the algorithm following exaction, the user enters SDMDNID at the Command or MS-DOS prompt and interactively enters: (1) site index (mean dominant height at 50 years breast-height age (m; Newton 1992)); (2) initial density regime (stems/ha); and (3) density interval between regimes (stems/ha). The algorithm graphically displays site-specific size-density trajectories for the eight specified initial density regimes from 10 to 100 years (e.g., Fig. 4) and the corresponding diameter distributions at 20-year intervals (e.g., Fig. 5). The resultant stand-level periodic yield estimates and associated grouped diameter frequency distributions are tabulated by 10-year intervals for each initial density regime. Complete operating instructions including references, users' notes, input requirements and limitations, are given during program execution.

\section{Discussion}

The Weibull PDF has been frequently utilized to characterize the diameter distribution within forest stands given its ability to describe a wide range of unimodal distributions with varying degrees of skewness (e.g., reversed-J shaped, exponential, and normal, among others). The results of this study indicated that the black spruce diameter frequency distributions within the sampled stands were well described by the Weibull distribution. Distributions ranged from reversed Jshaped to positively-skewed mound-shaped distributions as inferred from the shape parameter estimate $(0.9 \leq \hat{c} \leq 2.9)$. Expressing Weibull parameter estimates as functions of stand-level variables in order to recover diameter frequency distributions is an approach widely used in the development of stand-level distribution models (e.g., Schreuder et al. 1979, Little 1983, Rennolls et al. 1985, Mabvurira et al. 2002). Similarly, the results of this study indicated that Weibull param- 

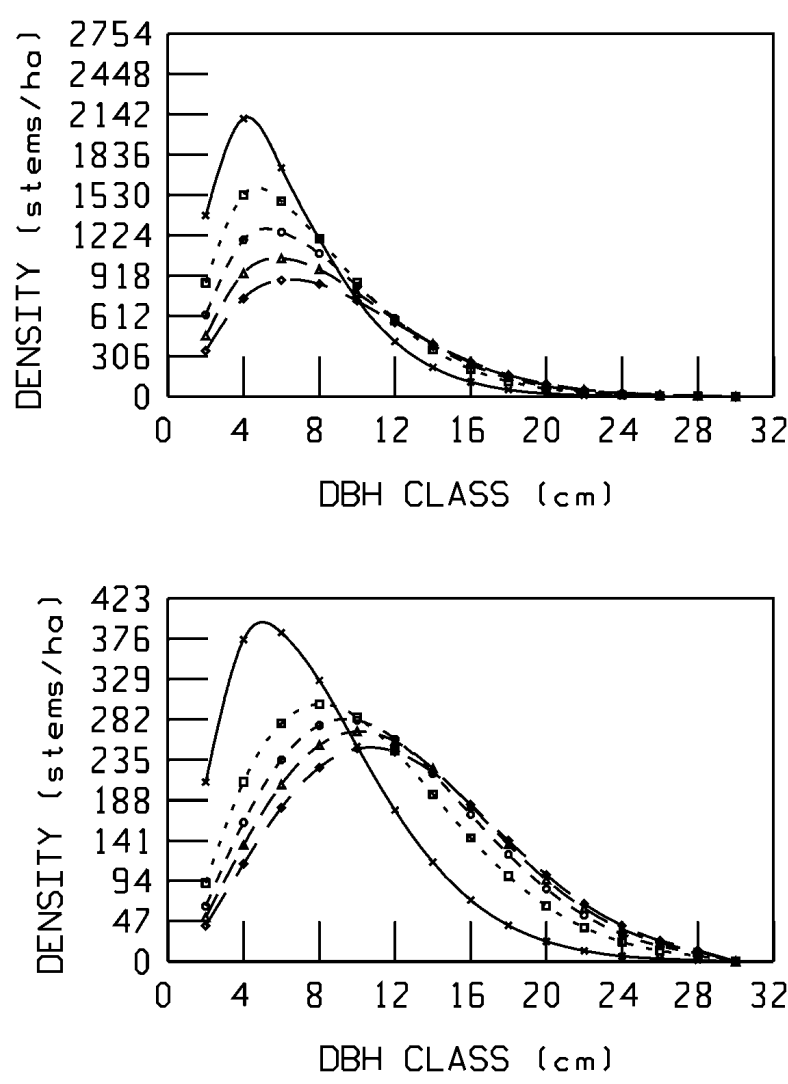

Fig. 5. Graphical illustration of the corresponding diameter frequency distributions at ages 20 (cross), 40 (square), 60 (circle), 80 (triangle) and 100 (diamond) yr for a 2000 stems/ha initial density regime (lower graph) and a 9000 stems/ha initial density regime (upper graph), as predicted from the sizedensity trajectories (Fig. 4) employing the parameter recovery approach (Fig. 3). eter estimates for the black spruce distributions could be adequately predicted by stand-level variables. The use of seemingly unrelated regression procedures in which the contemporaneous correlation of errors across equations was incorporated, resulted in more efficient parameter estimates than those that would be obtained via an equation-by-equation ordinary least squares procedure (Zellner 1962). Although the recovered diameter frequency distributions exhibited minimal predictive bias, the results suggested that the Weibull PDF may slightly overestimate the number of trees within the mid-lower size category (lower quartile) and slightly underestimate the number of trees within the mid-size category (middle quartiles). This systematic trend may be indicative of an underlying competition-induced semi-bimodal distribution that may occur during the intermediate stages of stand development (Newton and Smith 1988). However, the degree of bimodality was not of consequence given the acceptable level of predictive accuracy attained.

The approach described in this study may have general applicability in terms of the overall SDMD modeling approach. Currently, efforts are under way to develop similar models for other intensively managed boreal species. The practical outcome of this study includes the ability to predict the number of trees within each diameter class at various stages of stand development for a given initial density and site class. Such information is a basic prerequisite to addressing management objectives concerned with maximizing product value. For example, utilizing the diameter frequency distributions for the eight density regimes illustrated in Fig. 5 in combination with a generalized product value - diameter rela- tionship $\left(\right.$ product value $=f\left(\right.$ diameter $\left.^{3}\right)$ for trees greater than $12 \mathrm{~cm}$ in diameter (Zhang and Chauret 2001)), results in a relative stand-level product value increase at rotation (100 years) of $6.3,8.6,8.2,6.3,4.1$ and $2.9 \%$ for initial density regimes of 2000, 3000, 4000, 5000, 6000, 7000, and 8000 stems/ha, respectively, over the most dense regime considered (9000 stems/ha). Although conditional on the threshold diameter, range of initial densities and site indices considered, this example suggests that stand-level product value is maximized when the initial density is equivalent to approximately 3000 stems/ha.

\section{Conclusion}

The basic goal of this study was to extend an existing stand-level distance-independent average tree model (SDMD) to a stand-level distance-independent diameter distribution model employing a parameter prediction approach. The approach consisted of recovering the grouped diameter frequency distribution from the stand-level variables as predicted via the SDMD. Although numerous empirical-based distribution models have been developed (Porté and Barlelink 2002), the results of this study suggest the SDMD modelling approach is an acceptable framework upon which size distribution models can be developed. This has important practical implications given the large number of SDMDs which are already in use and hence potentially expandable. In order to address more complex density management regimes such as those involving thinning treatments, additional model refinement will be required within this expanded modelling framework. The approach described by 
Table 3. Variable definitions and associated computational details associated with the schematic illustrated in Fig. 3

\begin{tabular}{|c|c|}
\hline Variable & Description and computational details \\
\hline$S_{I}$ & User-specified site index (m): mean dominant height at 50 yrs (breast-height age) as defined by Eq. (3) in Newton (1992). \\
\hline$N_{I}$ & User-specified initial density (stems/ha). \\
\hline$\hat{H}_{d(t)}$ & $\begin{array}{l}\text { Predicted mean dominant height at time } t(\mathrm{~m}) \text {. Derived from the } S_{I} \text { function employing values of } t=10,20, \ldots, 100 \mathrm{yr} \text { and the associated vector } \\
\text { of parameter estimates, } \boldsymbol{\beta}_{S_{1}} \text { (Eq. (3) in Newton (1992)). }\end{array}$ \\
\hline$\hat{\bar{v}}_{(t)}$ & $\begin{array}{l}\text { Predicted mean volume at time } t\left(\mathrm{dm}^{3}\right) \text {. Derived from a two-stage regression procedure employing the reciprocal equation of the competition- } \\
\text { density effect using the first-stage parameter estimate vector, } \boldsymbol{\beta}_{R} \text { (Eqs. (7) and (8) in Newton and Weetman 1993), to predict the second-stage } \\
\text { parameter estimate vector, } \boldsymbol{\beta}_{\bar{v}(t)} \text { (Eq. (1) in Newton and Weetman 1993). }\end{array}$ \\
\hline$\hat{D}_{q(t)}$ & $\begin{array}{l}\text { Predicted quadratic mean diameter at breast height at time } t(\mathrm{~cm}) \text {. Estimated employing an empirically-derived regression relationship where } \\
\boldsymbol{\beta}_{D_{\mathrm{q}}} \text { denotes the parameter estimate vector (Eq. (9) in Newton and Weetman 1993). }\end{array}$ \\
\hline$\hat{P}_{r(t)}$ & $\begin{array}{l}\text { Predicted relative density index at time } t(\%) \text {. Derived from the asymptotic size-density (self-thinning) relationship for black spruce where } \boldsymbol{\beta}_{P_{r}} \\
\text { denotes the parameter estimate vector (Eq. (6) in Newton and Weetman 1993). }\end{array}$ \\
\hline$\hat{N}_{B(t)}$ & Predicted biotic density at time $t$ (stems/ha). Explicitly modelled using $N_{I}$ and $N_{A(t)}($ Newton and Weetman 1993). \\
\hline$\hat{N}_{A(t)}$ & $\begin{array}{l}\text { Predicted abiotic density at time } t \text { (stems/ha). Derived from an empirically-based mortality rate function }\left(R_{M(t)}\right) \text { which is used to predict the pro- } \\
\text { portion of trees that will incur mortality for stands within the zone of imminent competition mortality (ZICM) where } \boldsymbol{\beta}_{M} \text { denotes the parameter } \\
\text { estimate vector for the mortality rate function (Newton and Weetman 1993). }\end{array}$ \\
\hline$\hat{G}_{(t)}$ & Predicted basal area at time $t\left(\mathrm{~m}^{2} / \mathrm{ha}\right) .\left(\hat{G}_{(t)}=0.00007854 \cdot \hat{D}_{q(t)}^{2} \cdot \hat{N}_{B(t)}\right)$. \\
\hline$\hat{V}_{t(t)}$ & Predicted total volume at time $t\left(\mathrm{~m}^{3} / \mathrm{ha}\right) \cdot\left(\hat{V}_{t(t)}=1000 \cdot \hat{\bar{v}}_{(t)} \cdot \hat{N}_{B(t)}\right)$ \\
\hline$\hat{V}_{m(t)}$ & $\begin{array}{l}\text { Predicted merchantable volume at time } t\left(\mathrm{~m}^{3} / \mathrm{ha}\right) \text {. Estimated employing an empirically-derived regression relationship where } \boldsymbol{\beta}_{V_{m}} \text { denotes the } \\
\text { parameter estimate vector (Eq. (10) in Newton and Weetman 1993). }\end{array}$ \\
\hline$\hat{b}_{(t)}$ & Predicted scale parameter of the Weibull PDF (Eq. (1)) at time $t$ (Eq. (3) within text). \\
\hline$\hat{c}_{(t)}$ & Predicted shape parameter of the Weibull PDF (Eq. (1)) at time $t$ (Eq. (4) within text). \\
\hline$\hat{a}_{(t)}$ & Predicted location parameter of the Weibull PDF (Eq. 1) at time $t$ (Eq. (5) within text). \\
\hline$\hat{N}_{B(t, i)}$ & $\begin{array}{l}\text { Predicted number of trees (stems/ha) within the } i \text { th diameter class }\left(D_{(i)} \text { where } i=2,4, \ldots, 30\right) \text { at time } t \text { (Eq. (2) in combination with Eqs. (3), (4) } \\
\text { and (5)). }\end{array}$ \\
\hline
\end{tabular}

Álvarez et al. (2002) in which post-treatment Weibull parameter estimates are expressed as functions of pre-treatment Weibull parameters, degree of density reduction and type of thinning implemented, may be an appropriate starting point. Efforts to address this issue and to develop similar models for other intensively managed boreal conifers are continuing.

\section{Acknowledgements}

The authors express their appreciation to the reviewers for their constructive suggestions, and to the Natural Sciences and Engineering Research Council of Canada for fiscal support (Strategic Project Grant 234774).

\section{References}

Álvarez, J.G., J. Schröder, R.S. Rodríguez and A.D. Ruíz. 2002. Modelling the effect of thinning on the diameter distribution of even-aged Maritime pine stands. Forest Ecology and Management 165: 57-65.

Ando, T. 1962. Growth analysis on the natural stands of Japanese red pine (Pinus densiflora Sieb. et. Zucc.). II. Analysis of stand density and growth (in Japanese; English summary). Government of Japan, Bulletin of the Government Forest Experiment Station (Tokyo, Japan) No.147. 77 p.

Bailey, R.L. and T.R. Dell. 1973. Quantifying diameter distributions with the Weibull function. Forest Science 19: 97-104.
Brunsdon, B. 2000. A stand-level perspective of IFM in New Brunswick. In F.W. Bell, D.G. Pitt, M. Irvine, W.C. Parker, L.J Buse, N. Stocker, W.D. Towill, H. Chen, F. Pinto, K. Brown, D. DeYoe, T. McDonough, G. Smith and M. Weber (eds). Intensive forest management in Ontario - summary of a 1999 science workshop. p. 11. Government of Ontario, Ministry of Natural Resources, Sault Ste. Marie, Ontario, Canada. Science Development and Transfer Series 003.

Cleveland, W.S. 1979. Robust locally weighted regression and smoothing scatterplots. Journal of the American Statistical Association 74: 829-836.

Drew, T.J. and J.W. Flewelling. 1977. Some recent Japanese theories of yield-density relationships and their application to Monterey pine plantations. Forest Science 23: 517-534.

Drew, T.J. and J.W. Flewelling. 1979. Stand density management: an alternative approach and its application to Douglas-fir plantations. Forest Science 25: 518-532.

Gribko, L.S. and H.V. Jr., Wiant, 1992. A SAS template program for the accuracy test. Compiler 10: 48-51.

Hagner, M. 2000. Current forest management trends in Scandinavia. In F.W. Bell, D.G. Pitt, M. Irvine, W.C. Parker, L.J. Buse, N. Stocker, W.D. Towill, H. Chen, F. Pinto, K. Brown, D. DeYoe, T. McDonough, G. Smith and M. Weber (eds.). Intensive forest management in Ontario - summary of a 1999 science workshop. pp. 9-10. Government of Ontario, Ministry of Natural Resources, Sault Ste. Marie, Ontario, Canada. Science Development and Transfer Series 003. 
Jack, S.B. and J.N. Long. 1996. Linkages between silviculture and ecology: an analysis of density management diagrams. Forest Ecology and Management 86: 205-220.

Ker, M.F. 1974. Metric tree volume tables for Newfoundland. Government of Canada, Department of Environment, Canadian Forestry Service, Newfoundland Forest Research Centre, St. John's, Newfoundland. Information Report N-X-122. 24 p.

Kilkki, P., M. Maltamo, R. Mykkanen and R. Paivinen. 1989. Use of the Weibull function in estimating the basal area dbh-distribution. Silva Fennica 23: 311-318.

Kira, T., H. Ogawa and N. Sakazaki. 1953. Intraspecific competition among higher plants. I. Competition-yield-density interrelationship in regularly dispersed populations. Journal of the Institute of Polytechnics (Osaka City University, Japan), Series D 4: 1-16.

Little, S. N. 1983. Weibull diameter distributions for mixed stands of western conifers. Canadian Journal of Forest Research 13: 85-88. Mabvurira, D., M. Maltamo and A. Kangas. 2002. Predicting and calibrating diameter distributions of Eucalyptus grandis (Hill) Maiden plantations in Zimbabwe. New Forests 23: 207-223.

Newton, P.F. 1992. Base-age invariant polymorphic site index curves for black spruce and balsam fir within central Newfoundland. Northern Journal of Applied Forestry 9: 18-22.

Newton, P.F. 1997a. Stand density management diagrams: review of their development and utility in stand-level management planning. Forest Ecology and Management 98: 251-265.

Newton, P.F. 1997b. Algorithmic versions of black spruce stand density management diagrams. The Forestry Chronicle 73: 257-264.

Newton, P.F. and V.G. Smith. 1988. Diameter distribution trends within mixed and black spruce/balsam fir and pure black spruce stand types. Forest Ecology and Management 25: 123-138.

Newton, P.F. and G.F. Weetman. 1993. Stand density management diagrams and their utility in black spruce management. The Forestry Chronicle 69: 421-430.

Page, G. and R.S. van Nostrand. 1973. Empirical yield tables for the major forest cover types of Newfoundland. Government of Canada, Department of Environment, Canadian Forestry Service, Newfoundland Forest Research Centre, St. John's, Newfoundland. Information Report N-X-100. 84 p.

Porté, A. and H.H. Barlelink. 2002. Modelling mixed forest growth: a review of models for forest management. Ecological Modelling 150: 141-188.

Rennolls, K., D.N. Geary and T.J.D. Rollinson. 1985. Characterizing diameter distributions by the use of the Weibull distribution. Forestry 58: 57-66.
Reynolds, M.R., Jr. 1984. Estimating the error in model predictions. Forest Science 30: 454-469.

Rowe, J.S. 1972. Forest regions of Canada. Government of Canada, Department of Environment, Canadian Forestry Service, Ottawa, Ontario. Publ. No. 1300. 172 p.

Statistical Analysis System (SAS). 1999. SAS/OR User's Guide: Mathematical Programming. SAS OnlineDoc (http://v8doc.sas.com), SAS Institute Inc., Cary, NC.

Schreuder, H.T. and W.T. Swank. 1974. Coniferous stands characterized with the Weibull distribution. Canadian Journal of Forest Research 4: 518-523.

Schreuder, H.T., W.L. Hafley and F.A. Bennett. 1979. Yield prediction for unthinned natural slash pine stands. Forest Science 25: 25-30.

Shinozaki, K. and T. Kira. 1956. Intraspecific competition among higher plants. VII. Logistic theory of the C-D effect. Journal of the Institute of Polytechnics (Osaka City University, Japan), Series D 12: 69-82.

Terry, T. 2000. IFM: a Weyerhaeuser perspective. In F.W. Bell, D.G. Pitt, M. Irvine, W.C. Parker, L.J. Buse, N. Stocker, W.D. Towill, H. Chen, F. Pinto, K. Brown, D. DeYoe, T. McDonough, G. Smith and M. Weber (eds.). Intensive forest management in Ontario - summary of a 1999 science workshop. pp. 11-12. Government of Ontario, Ministry of Natural Resources, Sault Ste. Marie, Ontario, Canada. Science Development and Transfer Series 003.

Warren, G.R. and J.P. Meades. 1986. Wood defect and density studies. II. Total and net volume equations for Newfoundland's forest management units. Government of Canada, Department of Agriculture, Canadian Forestry Service, Newfoundland Forest Research Centre, St. John's, Newfoundland. Information Report N-X-242. 42 p.

Weibull, W. 1951. A statistical distribution function of wide applicability. Journal of Applied Mechanics 18: 293-297.

Yoda, K., T. Kira, H. Ogawa and K. Hozumi. 1963. Self-thinning in overcrowded pure stands under cultivated and natural conditions. Journal of Biology (Osaka City University, Japan) 14: 107-129. Zellner, A. 1962. An efficient method of estimating seemingly unrelated regressions and tests for aggregation bias. Journal of the American Statistical Association 57: 348-368.

Zhang, S.Y. and G. Chauret. 2001. Impact on initial spacing on tree and wood characteristics, product quality and value recovery in black spruce (Picea mariana). Canadian Forest Service Report No. 35, Forintek Canada Corp., Sainte-Foy, Quebec. 47 p. 